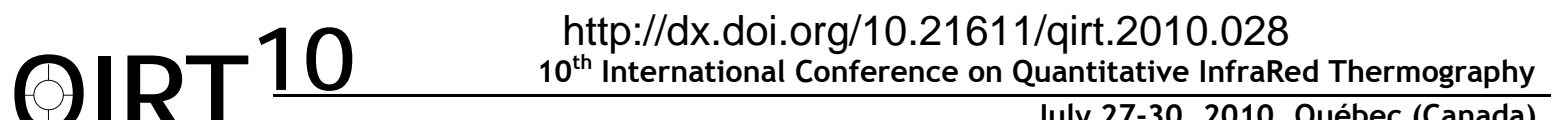 \\ July 27-30, 2010, Québec (Canada)
}

\section{Assistance to the restoration of historical frescoes by stimulated infrared thermography}

\author{
by J.C. Candoré* ${ }^{*}$ J.L Bodnar*, V. Detalle** and P. Grossel*
}

\author{
*GRESPI/ECATHERM, UFR Sciences Exactes et Naturelles, BP 1039, 51687 Reims cedex 02, France \\ ** LRMH, 29 avenue du Paris, 77420 Champs sur Marne, France \\ (jl.bodnar@univ-reims.fr)
}

\begin{abstract}
In this paper, different examples of assistance to restoration of mural paintings by stimulated infrared thermography are presented. First, we present the principle of this non destructive method. We present then the device of stimulated infrared thermography implemented for the study. We show finally, the possibility of detecting, in situ, by this technique, detachment situated in the Saint Christopher of the "Campana" collection of "Louvre", in walls painted of the church "Saint Florentin de Bonnet", in ceilings painted of the abbey of "Saint Savin sur Gartemp"e (classified in the UNESCO world heritage) and finally in the frescoes "Cocteau" of the vault "Saint Pierre of Villefranche sur Mer".
\end{abstract}

\section{Introduction}

In the field of assistance to the restoration of works of art, restorers use several methods and physical and chemical instruments. Without being exhaustive, we can quote the visible photography, the photography ultraviolet, the infrared photography (implementation in natural light, in polarized light) the X-ray radiography, the electronic scanning microscopy, the spectroscopy, the chromatography in liquid phase or vapor phase, the particle accelerator AGLAE, the acoustic sounding,... These methods, very diverse, are very successful in their fields of application but, are naturally, not universal. Besides, their principle of implementation can make certain of them boring and tiring to implement. We can quote, for example, the detection of defects in mural paintings (being able to extend in churches over a huge surface) by acoustic analysis, the sound source of which is the tapping of the index of the restorer on the work of art. New checking procedures, destructive or non-destructive can find thus again their place in the field of the assistance to the restoration of works of art.

The scientific community works for more than 20 years, in the development of a particular non-destructive testing procedure: the stimulated infrared thermography. This mode of control is non-destructive, without contact and is used for the thermophysical analysis of thin materials. It was already implemented to detect and characterize various types of defects (detachments, cracks, inclusions), localized or widened, in various types of materials [1-5]. It thus seems to be able to be of a possible use in the field of the restoration of works of art, to help for example in the restoration of mural paintings, in a complementary way with the acoustic analysis. It explains that, from now on several years, several research teams, including ours, have implemented it in this frame [6-14].

In this work, it is then; various examples of results obtained by our team are presented. We show, the possibility of detecting, in situ, by this technique, detachments situated in "Saint Christopher" of the "Campana" collection of "Louvre", in walls painted of the church "Saint Florentin" de "Bonnet", in ceilings painted of the abbey of "Saint Savin sur Gartempe" (classified in the UNESCO world heritage) and finally in the frescoes "Cocteau" of the vault "Saint Pierre" of "Villefranche sur Mer".

\section{Principle of non destructive testing by stimulated infrared thermography}

The principle of the stimulated infrared thermography is relatively simple. It consists in subjecting the sample to be analyzed in a flow of photons which absorption produces a local rise of temperature in the neighborhood of the luminous impact point, then to observe the variations of emission of the material by means of a camera of infrared thermography. The thermophysical phenomena mainly implemented by this testing procedure are the conduction and the thermal radiation.

The photothermal signal collected by the infrared radiometer thus depends on parameters governing these physical phenomena (thermal conductivity, thermal diffusivity, emissivity, temperature, specific heat, density), but also on all the parameters being able to be correlated to these last ones (aspect of surface, presence of detachment, presence of crack, progress of a physico-chemical transformation, a drying, a sedimentation). The principle of the method makes that it is nondestructive, without contact, flexible and easily customizable according to needs 


\section{The device of stimulated infrared thermography implemented for the analysis of mural paintings}

As we have just seen it the stimulated infrared thermography is a procedure of very flexible and customizable nondestructive control according to needs. There are thus numerous manners to implement it and consequently of numerous types of experimental devices. Let us examine the logical approach which led us to choose the various elements of the experimental device implemented to end in the detection in situ of air pocket or detachment situated in mural paintings.

The "industrial" character of this application as well as the need of portability which requires an analysis in situ, led us to implement the simplest experimental device and the most sturdy possible.

Besides, the potential dimensions of the defects to be detected being rather important, we chose to implement a extent analysis, both for the excitation and for the infrared detection.

The "industrial" character of this application, has still led us to plan the use of a pulsed excitation and the use of the least expensive possible equipments (to facilitate a possible technology transfer).

So, we chose projectors with industrial halogens to excite in an impulsive way, mural paintings to be analyzed, a camera of infrared thermography (for example of type A20 from FLIR) to assure the collection of the information and finally an electronics and a computing of piloting of the instrumentation allowing a photothermal analysis (fig. 1.).

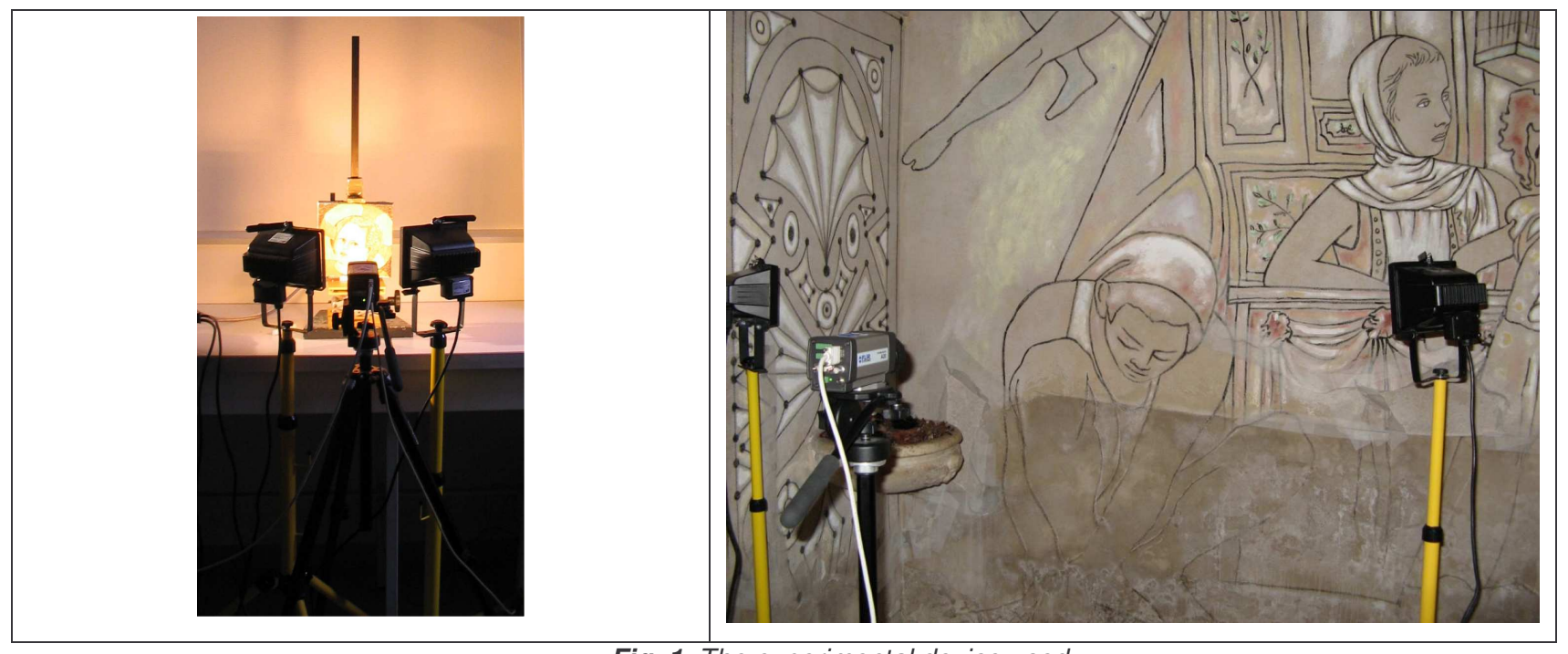

Fig. 1. The experimental device used

\section{Analysis of mural paintings: examples of experimental results obtained}

The first type of mural painting we analyzed is a partial copy of the Saint Christopher of the "Campana" collection of "Louvre". It acts, as shows in the fig. 2 a of a fresco realized according to the technique of primitive Italian, in a mixture of lime and plaster, the whole being covered with a pictorial layer, which represents here the infant Jesus.

This fresco, realized initially as sample of pre-study with the aim of the analysis of the "saint Christopher" itself, contains 4 defects: 4 inclusions of "plastazote" (fig. 2b).

To detect these defects, we analyzed this fresco by stimulated infrared thermography. An example of result obtained is presented on the fig. 2c. It clearly shows a more important infrared signature towards the defects. These characteristic signatures are due to the more insulating thermal properties of the "plastazote" with regard to the mixture lime / plaster. Indeed our operating mode consists in exciting our sample with the visible light. This light, during an interaction radiation / material warms slightly the surface of the work of art. This heating propagates then by conduction in the fresco. Towards the defects, constituted essentially by air and thus more insulating thermically than the mixture lime / plaster on which was put deposited the pictorial layer, this distribution was slowed down. It follows itself a less fast cooling of the surface enlightened in the right of the defects and thus an infrared signature more important for this location. 

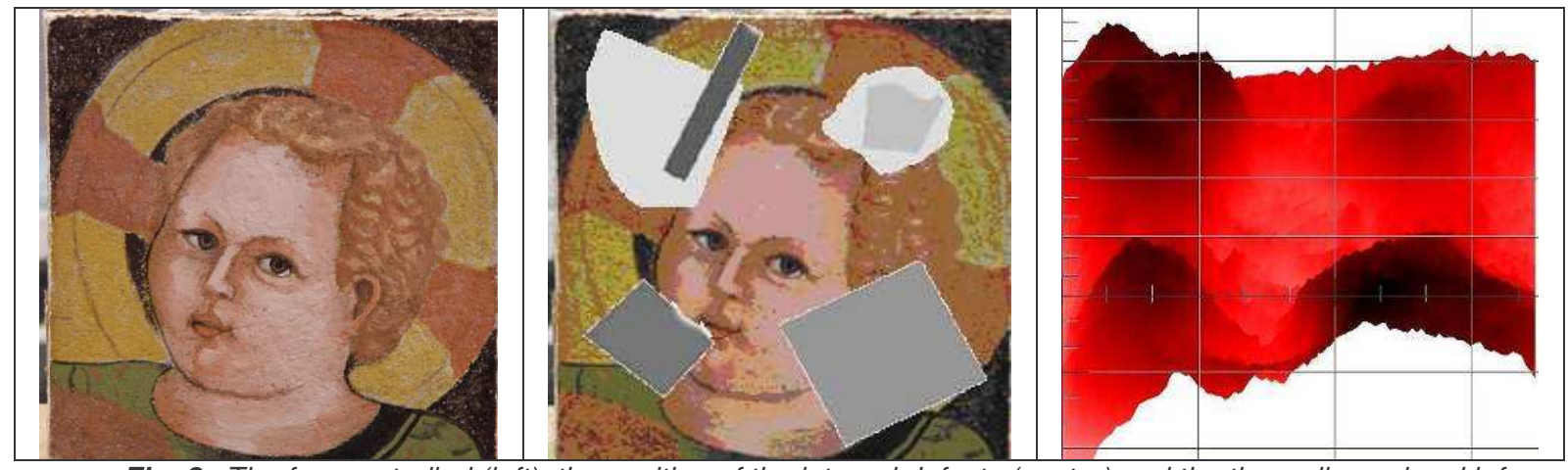

Fig. 2. The fresco studied (left), the position of the internal defects (center) and the three-dimensional infrared photothermal image obtained (right)

The results were obtained on the test fresco being encouraging and effectively non-destructive, we analyzed secondly the "Saint Christopher" itself. This work of art represents "Saint Christopher" carrying the infant Jesus and is attributed to "Tommaso del Mazza". It was created between 1385 and 1390. It is a part of the "Campana" collection of "Louvre" (fig. 3a). This fresco was analyzed at first in an acoustic way by Gabriella Szatanick, restorer of the heritage. We then analyzed it, area by area, to obtain a sufficient optical resolution for each image, by pulsed photothermal radiometry. The obtained results are compared on the fig. $3 c$ to those obtained by acoustic analysis (fig. $3 b$ ). On this figure, we notice on one hand, that the characteristic signatures of visible defects by photothermal radiometry (green and yellow areas) correspond to areas of detachment detected by the acoustic method (grey area). We notice on the other hand, that in the conditions of implementation of the photothermal method (pulsed excitation of 2 minutes duration), the defects detected by the photothermal method are less many than by the acoustic method. Apparently, it is due to duration of too short excitation, not allowing the detection of the deepest defects (example of the defect situated above on the right by the mural painting). We have still noticed, experimentally, that the defects detected at the same moment by photothermal radiometry, gave birth to the same tone by acoustic sounding, what confirms that they had to be approximately situated in the same depth. The photothermal analysis thus seems to open the way to a dimensional characterization of the defects, difficult by acoustic way. Finally, we verified that the acquisition of information by photothermal radiometry is certainly effectively faster and more objective than the acoustic analysis.
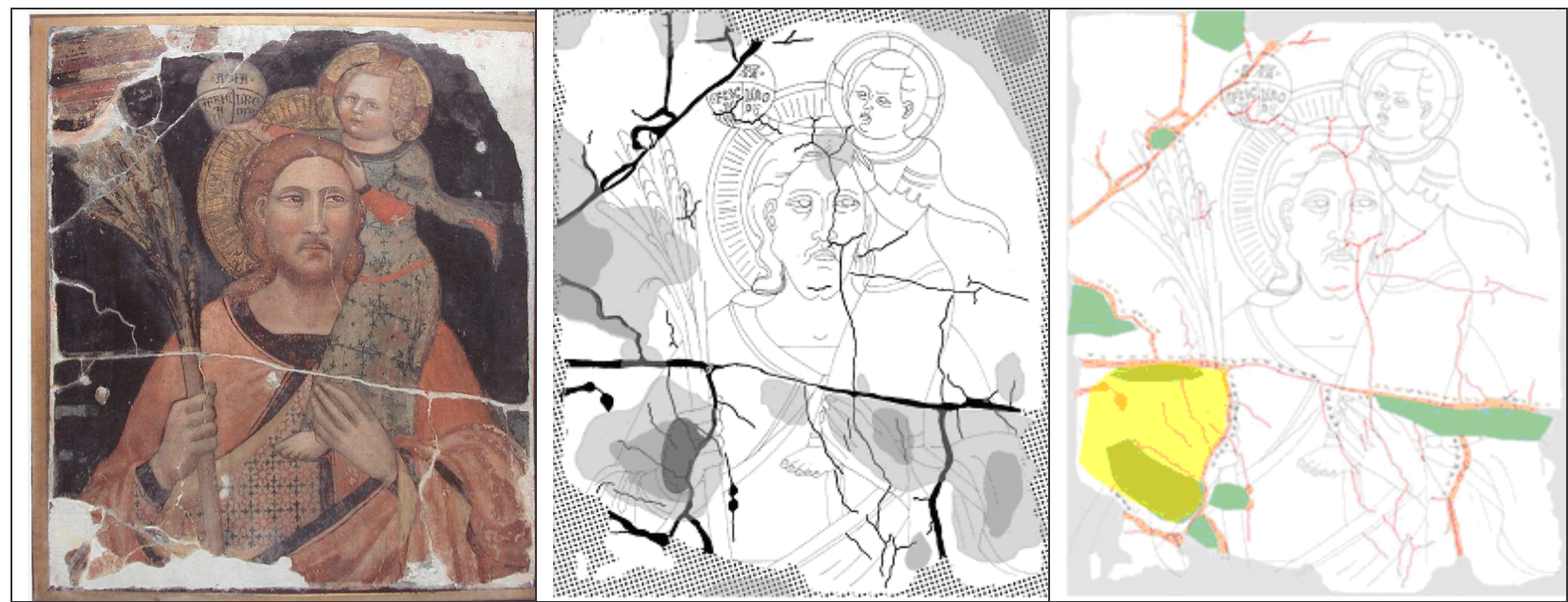

Fig. 3. The fresco of Saint Christopher studied (left) and the experimental results obtained during the acoustic analysis (center) and photothermal (right)

The third mural painting we studied is a painting mounted on canvas, dating the 19th century, of the apse of the church of "Bonnet". We were able to obtain, thanks to the help of the "ANDRA" and the City Council of the village of "Bonnet", a few hours to proceed a photothermal analysis in situ. The fresco we studied represents "Saint Martin" (fig. 4a). 


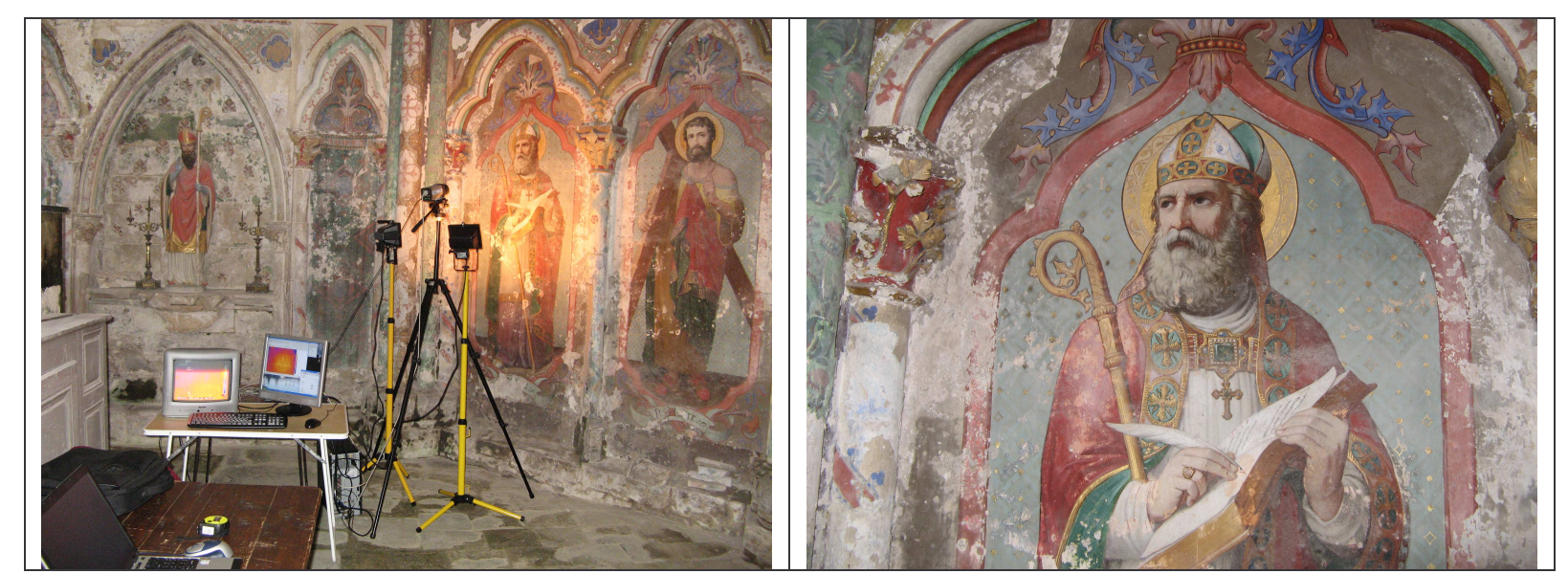

Fig. 4. The apse (left) and the painting mounted on canvas "Saint Martin" (right) of the church Saint Florentin of Bonnet

We have first of all and as in the previous cases, analyzed this painting mounted on canvas in an acoustic way. The statement obtained makes appears a multitude of "hollow" tones, restarted rather in periphery of the work of art (fig. 5a). We then analyzed this painting mounted on canvas by pulsed infrared thermography and continuous detection (excitation of 5 minutes). An example of result obtained is presented on the fig. 5b. It shows more important, significant photothermal signatures of the presence of defects, in locations referenced by the acoustic analysis.

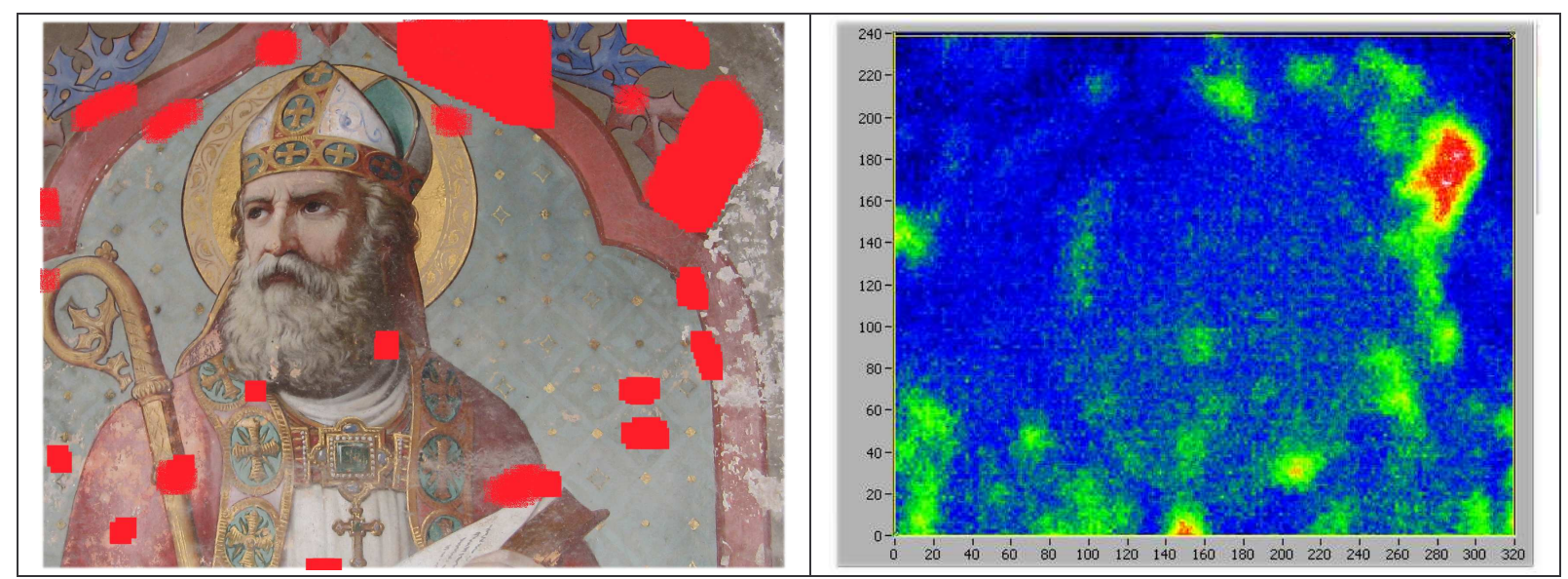

Fig. 5. The experimental results obtained during the acoustic analysis (left) and photothermal (right).

The fourth mural painting we studied is located in the nave of the abbey of "Saint Savin sur Gartempe". This Abbey is classified since 1984, because of the exceptional quality of the murals paintings which it contains, in the UNESCO world heritage. Most of these paintings were realized at the end of the $\mathrm{XI}^{\text {th }}$ century and are characteristic of Roman period. They represent religious themes inspired by the Bible, the major source for the art of the Middle Ages: they are the Apocalypse, the Passion, the Resurrection of the Christ and many other analogues. The cradle of the nave, the length of more than 40 meters, is completely covered with paintings on a surface about $500 \mathrm{~m}^{2}$. They illustrate the Genesis and the Exodus (Fig. 6.). 


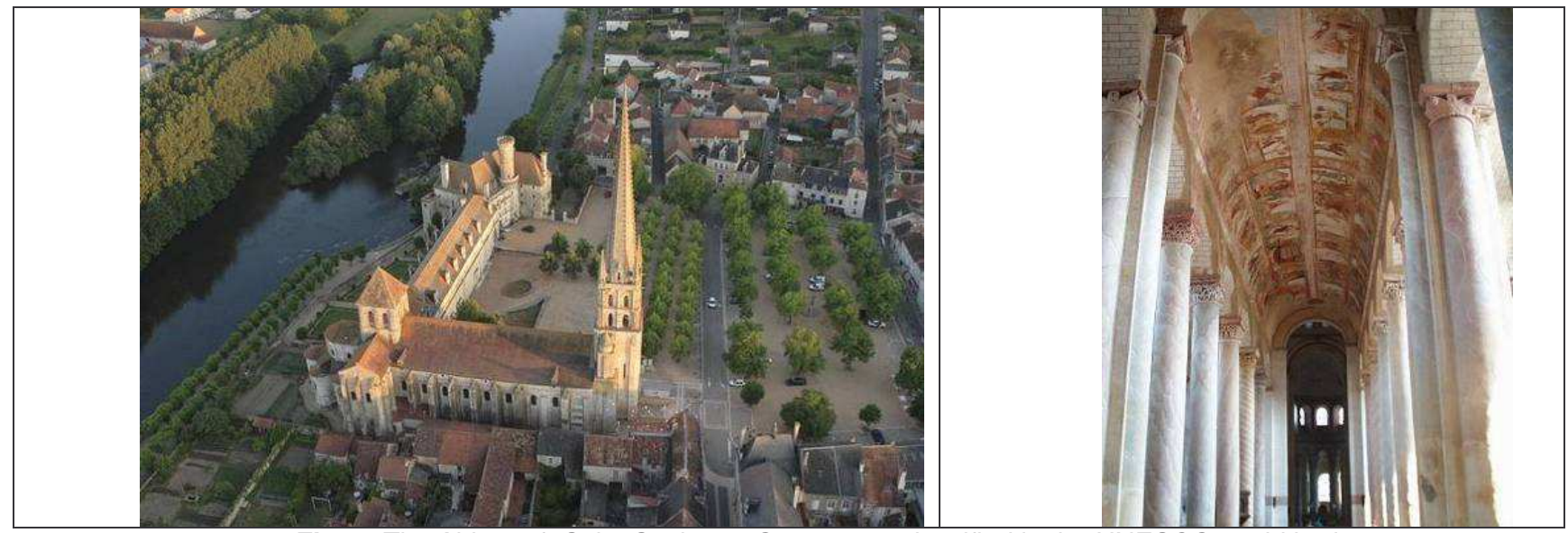

Fig. 6. The Abbey of "Saint Savin sur Gartempe", classified in the UNESCO world heritage, and the exceptional mural paintings.

Several campaigns of restoration of mural paintings took place. The first one was realized by "Prosper Mérimée" in 1835. In 1967 a second campaign of restoration in aimed the paintings of the narthex, the vaults of the nave and both crypts. Finally, since 2005, a new campaign of restoration of the paintings of the nave began. It is in this frame and as a supplement to the acoustic statements made by restorers' team working on the construction site ("Brice Moulinier", "Emmanuelle Cante") that intervenes our study. This last one aimed on one hand at confirming, even at completing the statements of the restorers. It also had for objective to test the possibilities of the stimulated infrared thermography in real conditions of restoration (on a scaffolding, in the dust, in the cold, at the same time in the other types of analyses, at the same time as works of restoration, in a limited time). The mural painting we studied is a part of the fresco of the "La traversée du désert ", more particularly the zone surrounding the back wheel of the char (fig. 7.).

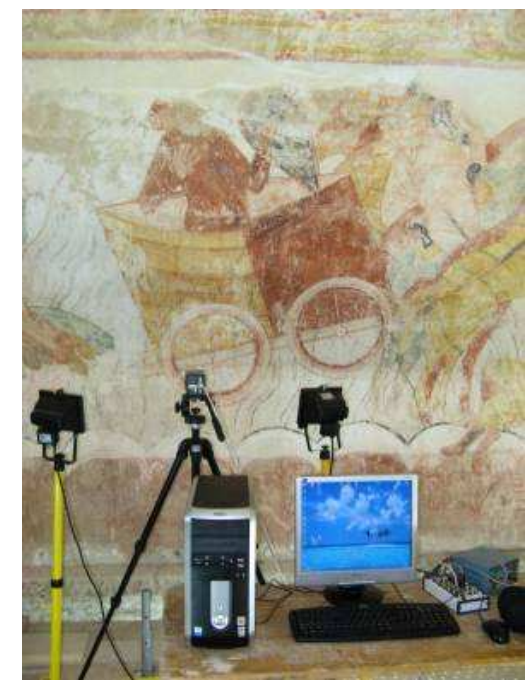

Fig. 7. The mural painting studied, "La traversée du désert"

The statement made by the professional restorers is presented on the fig. 8a. It makes appears abnormal acoustic signatures in the lower and superior parts of the wheel of the char. We then analyzed this fresco by pulsed photothermal analysis. An example of result obtained is presented on the fig. 8b. This last one shows more important, significant photothermal signatures of the presence of defect, in location referenced by the acoustic analysis: in low and high parts of the wheel of the char. However in the case of the photothermal analysis, these two signatures are not uniform but seem to indicate the presence of two separate defects, while the acoustic analysis had detected only one. A new acoustic statement 
made by restorer's team then confirmed the presence of two separate defects in both cases. The photothermal method thus seems to allow a detection at once, more precise of the position of the defects, that the acoustic method. These images also show that the photothermal method seems to be able to be implemented, in situ and in real conditions of restoration.

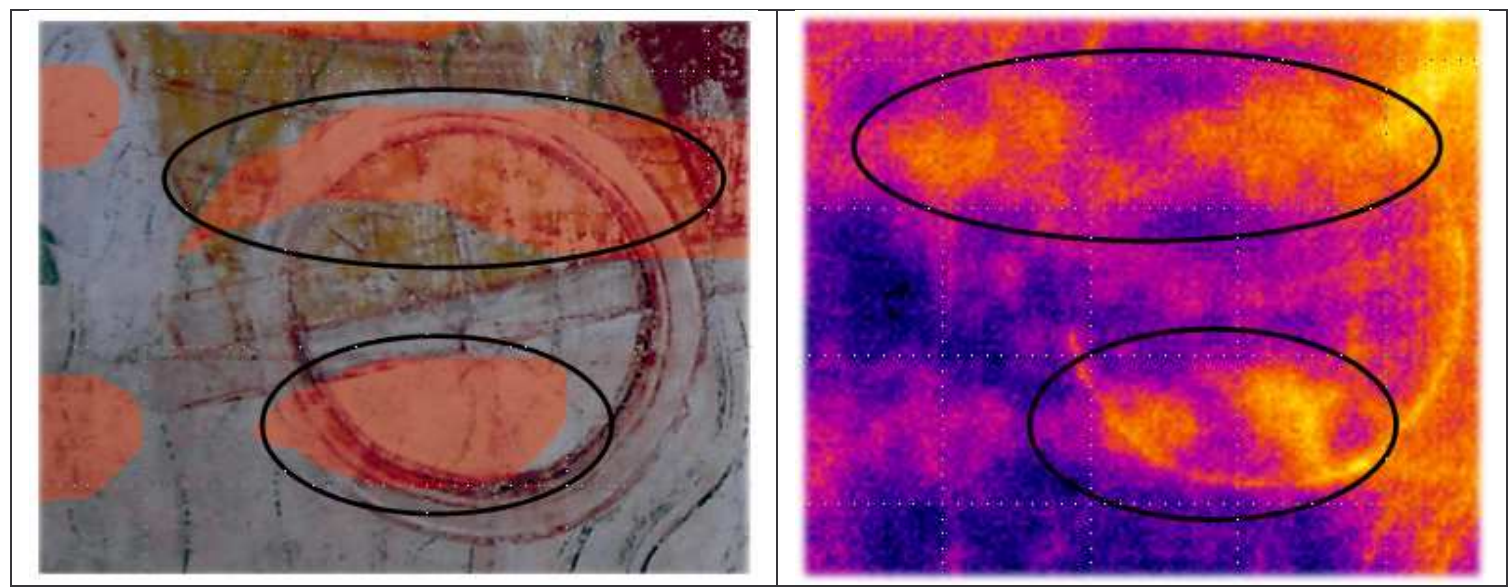

Fig. 8. The experimental results obtained during the acoustic analysis (left) and photothermal (right) of the mural painting "La traversée du désert"

The fifth mural painting we studied is the entitled mural "Hommage aux pécheurs de Sainte Marie " of the vault "Saint Pierre" of "Villefranche sur Mer" (fig. 9).

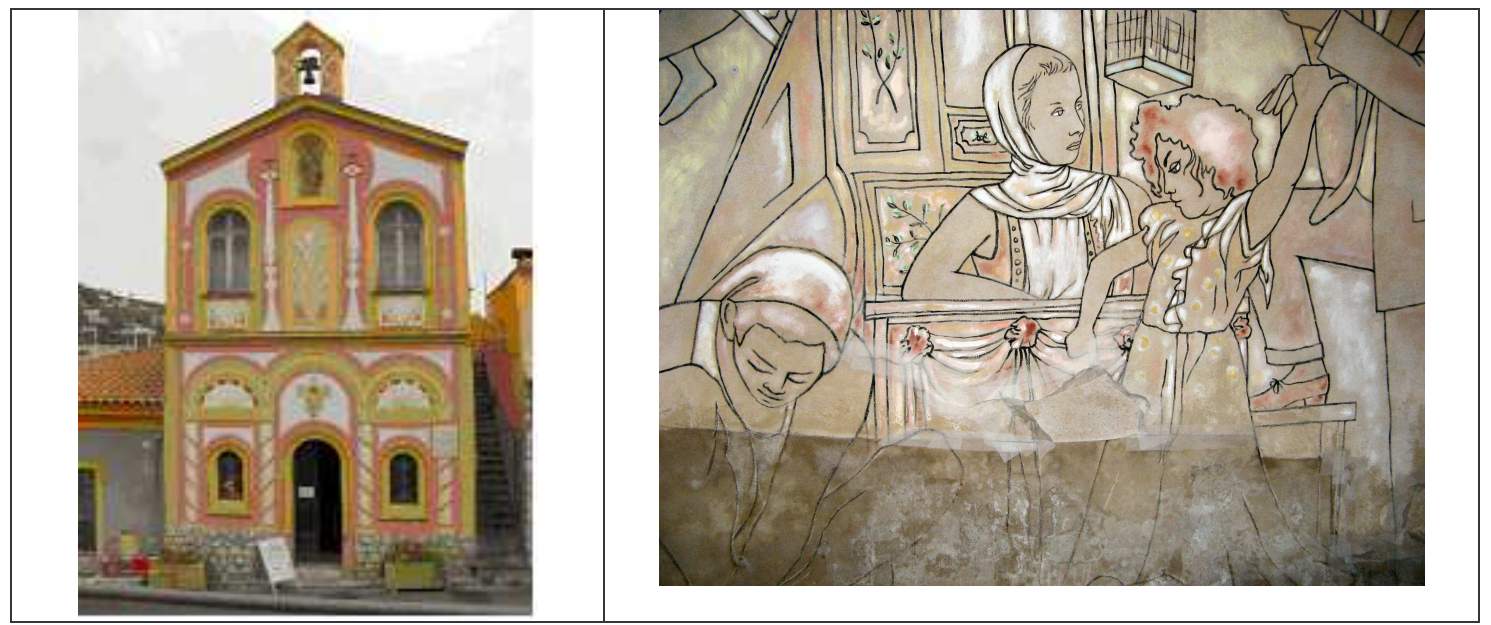

Fig. 9. The vault Saint Pierre of Villefranche sur Mer (left) and the mural paintings "Hommage aux pécheurs de Sainte Marie " (right) realized by Jean Cocteau

This mural painting was realized by Jean Cocteau in 1956-57. The mural paintings of the vault, relatively recent already undergo the effects led by their environment and by the behavior of visitors. They are already slightly degraded. A fast, preliminary acoustic statement in a restoration was made, for all the mural paintings of the vault, by restorers' team. It shows the presence of certain number of defects, as detachments, rashes of salts, blister or still peeling of. The mural painting studied is a part the fresco "Hommage aux pécheurs de Sainte Marie" (fig 10). 


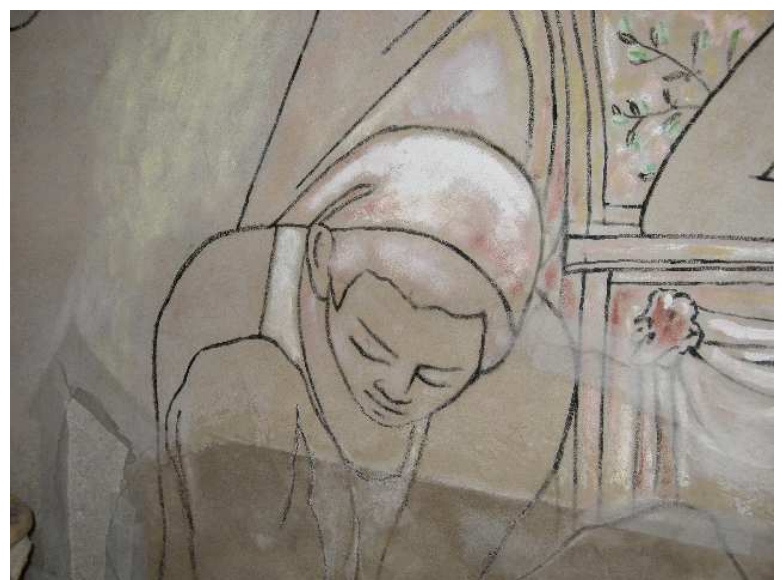

Fig. 10. The part of the mural painting "Hommage aux pécheurs de Sainte Marie" studied

As regards the part of the mural painting studied, the restorers (fig. 11a) detected an important partially central detachment of the fresco (red hatchings), a fall of the filler supporting the lower left pictorial layer of the work of art (purple dot) and finally on the straight part of the drawing, a band of Japan paper to strengthen the same filler, certainly more altered in this place (purple line). The object of the photothermal analysis was in this fifth study, on one hand to try to confirm the acoustic statement. It was necessary on the other hand, in real conditions, to try to improve the precision of the rather unrefined acoustic statement. It was finally necessary to confirm again, the possibilities of the infrared thermal imaging stimulated in detection in situ of defects situated in mural paintings.

An example of photothermal image pulsed obtained is presented on the fig. $11 \mathrm{~b}$

It confirms at first the results obtained by acoustic analysis, that is a detachment seems good to exist in the analyzed area and that is a lack of filler is detected in the left bottom of the work of art.

It then seems to show a finer statement of the outline of this area of detachment, than the acoustic analysis, what presents certain interest for the restorers of the heritage.

It finally shows a more important photothermal signature to the right of the infrared thermogram, in the location or was put by some Japan paper to strengthen the work of art (thus locally more fragile).

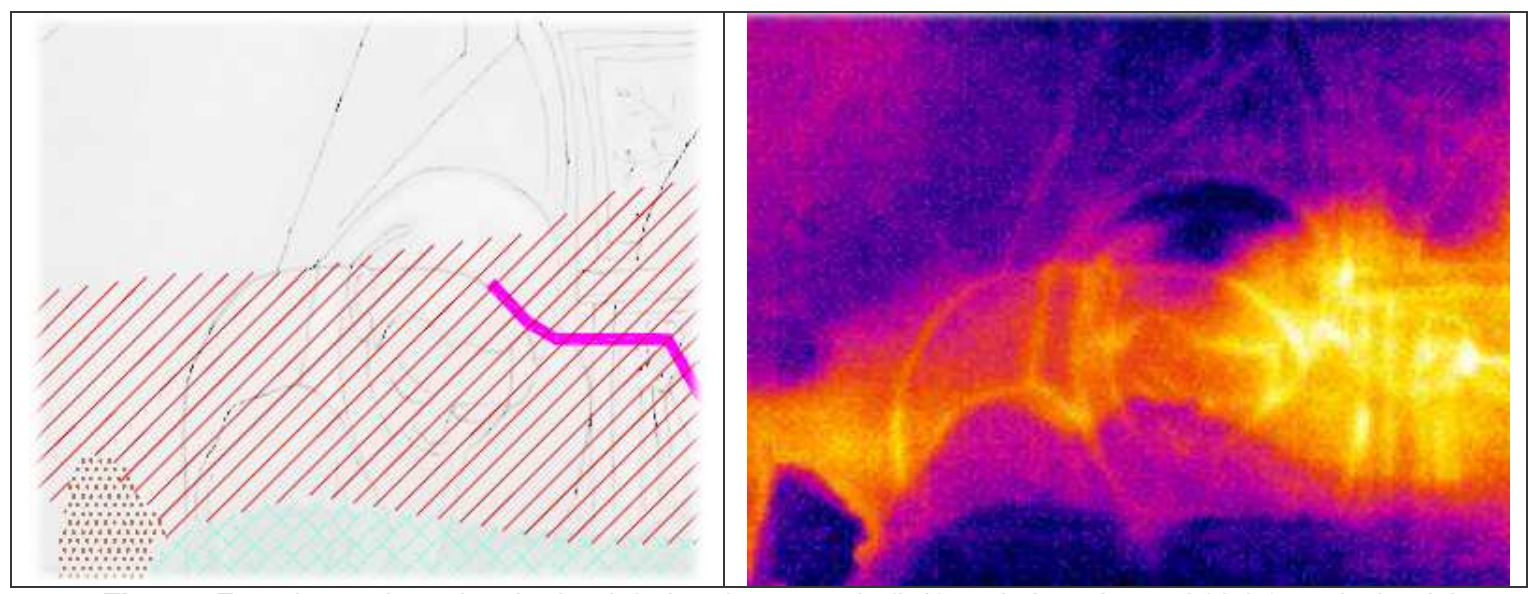

Fig. 11. Experimental results obtained during the acoustic (left) and photothermal (right) analysis of the mural painting "Hommage aux pécheurs de Sainte Marie" 


\section{Conclusion}

In this work, we presented various examples of assistance to the restoration of mural paintings by stimulated infrared thermography.

We presented at first the principle of this procedure of non-destructive control.

We then presented the device of stimulated infrared thermography implemented for the study.

We finally showed, the possibility of detecting by this technique, air pocket or detachment situated in the "Saint Christopher" of the "Campana" collection of "Louvre", in walls painted of the church "Saint Florentin" of "Bonnet", in ceilings painted of abbey "Saint Savin sur Gartempe" (classified in the UNESCO world heritage) and finally in the frescoes "Cocteau" of the vault "Saint Pierre" of "Villefranche sur Mer". paintings.

These results show at first that the photothermal method indeed allows detecting in situ defects situated in murals

They show then that the results obtained by infrared photothermal analysis are correlated to those obtained by acoustic analysis.

They still show, that the photothermal method seems, with regard to the acoustic method, to allow a more precise, faster and more objective detection of these defects (even less destructive as regards the placed defects near immediate of the surface of the mural, that an acoustic analysis could damage).

They show finally, that the photothermal method seems useful in situ and in real conditions of restoration of mural paintings (on a scaffolding, in the dust, in the cold, at the same time in the other types of analyses, at the same time as works of restoration, in a limited lapse of time) to help in the restoration of this type of work of art.

These very encouraging results ask now to be confirmed and completed. There is at first to define and to implement the photothermal variant which will lead to the most complete possible analysis of the works of art while perturbing them the least possible (random analysis?). There is then to study the quantitative possibilities (in terms of dimensional characterization of defects) of the photothermal method. Studies going to this direction are in progress

\section{REFERENCES}

[1] Maldague Xavier: Theory and practice of infrared technology for non destructive testing

[2] V.P. Vavilov : Non destructive testing handbook : thermal / infrared testing

[3] Jean Charles Candoré, Jean Luc Bodnar, Antoine Szeflinski et Laurent lbos: Helps with the thermal diagnosis of the building: Detection of defects of insulation by stimulated infra-red thermography procceding of qirt 2008 , Cracovie, Poland.

[4] S. Maillard, J. Cadith, H. Walaszeh, A. Dillenz et J.L. Bodnar: Lock in thermography toward a new online ndt method? Janvier 2009, e-journal of non-destructive testing, pp 10, id 7140.

[5] S. Brahim, J.L. Bodnar et P. Grossel : Thermal diffusivity measurement by photothermal radiometry under random excitation and parametric analysis, Proceeding of 15th International Conference on Photoacoustic and Photothermal Phenomena 2009 , Leuven, Belgium

[6] V. Tornari, E. Esposito, V. Zafiropulos, N. Paone, C. Fotakis, E.P. Tomasini, N. Smyrmakis, S. Stassinopulos, M. Stefanaggi, «Non invasive laser mesurement for diagnosing the state of conservation of frescoes and wooden icons ", 4th European Commission Conference on Researchfor protection, conservation and enhancement of cultural heritage : Opportunities for European enterprises, Strasbourg, 2000, p. 74-80.

[7] T. Fricke-Begemann, G. Gülker, K.D. Hinsch, H. Joost, „Remote localisation of debonded areas in historical murals by TV-holography“ 1999, p. 247-255 ; Schirripa Spagnolo, Guattari, Grinzato, 1999.

[8] E. Grinzato, P.G. Bison, S. Marinetti, V. Vavilov, : Activ thermal testing of delaminations in frescoes' plaster, 4th International Conference on Non-destructive Testing of Works of Art, Berlin,1994, p. 357-367

[9] G. Schirripa Spagnolo, G. Guattari, E. Grinzato : Frescoes Diagnostics by electro-optic holography and infrared thermography, $6^{\text {th }}$ World Conference on NDT and Microanalysis in Diagnostics and Conservation of Cultural and Environnemental Heritage, Rome, 1999, p. 385-398.

[10] S. G. Tavares,A. Agnani, E. Esposito, M. Feligiotti, S. Rocchi , R. M. de Andrade : Comparative study between infrared thermography and laser Doppler vibrometry applied to frescoes diagnostic Proceeding of the QIRT2006 congress, Padoue, 2-4 July 2006 Italie

[11] Jean Charles Candoré*, Gabriela Szatanik, J.L Bodnar*, Vincent Detalle, Philippe Grossel : Infra-red photothermal thermography: A tool of assistance for the restoration of murals paintings? Proc of QIRT2006, Padoue, Italy

[12] Jean Charles Candoré, J.L Bodnar, Vincent Detalle, Philippe Grossel : Non destructive testing of works of art by stimulated infrared thermography, procceding of QIRT 2008, Cracovie, Pologne

[13] Jean Charles Candoré, J.L Bodnar, Françoise Depasse, Vincent Detalle, Philippe Grossel : Approach of the characterization of delamination in mural paintings, procceding of QIRT 2008, Cracovie, Pologne

[14] Jean Charles Candoré, J.L Bodnar, Vincent Detalle, Philippe Grossel : Non destructive testing of mural paintings, in situ, by infrared photothermal radiometry, Procceding de SMW08, Florence, Italy 